\title{
Hippocampus and its involvement in Alzheimer's disease: a review
}

\author{
Y. Lakshmisha Rao ${ }^{1}$ B. Ganaraja ${ }^{2}$ - B. V. Murlimanju ${ }^{1}$ (1) $\cdot$ Teresa Joy $^{3} \cdot$ Ashwin Krishnamurthy $^{4} \cdot$ Amit Agrawal $^{5}$
}

Received: 20 December 2021 / Accepted: 16 January 2022 / Published online: 1 February 2022

(c) The Author(s) 2022

\begin{abstract}
Hippocampus is the significant component of the limbic lobe, which is further subdivided into the dentate gyrus and parts of Cornu Ammonis. It is the crucial region for learning and memory; its sub-regions aid in the generation of episodic memory. However, the hippocampus is one of the brain areas affected by Alzheimer's (AD). In the early stages of AD, the hippocampus shows rapid loss of its tissue, which is associated with the functional disconnection with other parts of the brain. In the progression of $\mathrm{AD}$, atrophy of medial temporal and hippocampal regions are the structural markers in magnetic resonance imaging (MRI). Lack of sirtuin (SIRT) expression in the hippocampal neurons will impair cognitive function, including recent memory and spatial learning. Proliferation, differentiation, and migrations are the steps involved in adult neurogenesis. The microglia in the hippocampal region are more immunologically active than the other regions of the brain. Intrinsic factors like hormones, glia, and vascular nourishment are instrumental in the neural stem cell (NSC) functions by maintaining the brain's microenvironment. Along with the intrinsic factors, many extrinsic factors like dietary intake and physical activity may also influence the NSCs. Hence, pro-neurogenic lifestyle could delay neurodegeneration.
\end{abstract}

Keywords Alzheimer's disease $\cdot$ Hippocampus $\cdot$ Sirtuin $1 \cdot$ Tau proteins

\section{Introduction}

The cerebral cortex and hippocampus are closely associated with cognitive function and neurogenesis in the brain $\mathrm{CHu}$ et al. 2019). Along with the $\beta$-amyloid and tau proteins, transactive response deoxyribonucleic acid (TAR DNA)-binding protein of $43 \mathrm{kDa}$ (TDP-43) is also a newly linked protein in the AD. TDP-43 protein accumulates in the amygdala

B. V. Murlimanju

flutesnowmm@gmail.com

1 Department of Anatomy, Kasturba Medical College, Mangalore, Manipal Academy of Higher Education, Manipal, Karnataka, India

2 Department of Physiology, Kasturba Medical College, Mangalore, Manipal Academy of Higher Education, Manipal, Karnataka, India

3 Department of Anatomy, College of Medicine, American University of Antigua, Coolidge, Antigua, Antigua and Barbuda

4 Department of Anatomy, K.S. Hegde Medical Academy, Deralakatte, Nitte University, Mangalore, Karnataka, India

5 Department of Neurosurgery, All India Institute of Medical Sciences, Saket Nagar, Bhopal 462020, Madhya Pradesh, India and spreads into the hippocampus, leading to faster atrophy (Josephs et al. 2017). Hence, prevention of spreading this protein into the hippocampus could treat AD (Josephs et al. 2017). The genetic neuroimaging works have proved that the AD risk alleles show a crucial role in cortical and hippocampal morphometry (Lancaster et al. 2019). In AD, neuronal degeneration happens because of the accumulation of two abnormal proteins, $\beta$-amyloid, and tau, in the brain. The characteristic feature of AD is an excessive formation or decreased elimination of amyloid-beta (A $\beta)$. Microscopically and pathologically, $\mathrm{AD}$ is described as the extracellular accumulation of senile plaques in addition to the intracellular accumulation of the neurofibrillary tangles in various parts of the brain, particularly in the hippocampus (Chu 2012).

Along with the deposition of abnormal proteins, the AD brain also shows the degeneration of the hippocampus (Josephs et al. 2017). Hippocampus is a vital region of the memory, and this part of the brain shows adult neurogenesis (Poo et al. 2016). In old age, the hippocampus is affected by cognitive decline, which is also seen in neurodegenerative disorders like AD (Jaroudi et al. 2017). Though hippocampal degeneration is also seen in other neurodegenerative diseases like Lewi body dementia, the degree of deterioration is markedly more in AD. The knowledge of variation in the 
hippocampus will help diagnose and treat $\mathrm{AD}$ (Elder et al. 2017). The patients with AD are clinically presented with the deterioration of activity of daily living due to the cognitive and functional decline (Chu 2012).

\section{Subdivisions of hippocampus (Fig. 1) and the Papez circuit}

The subdivisions of the hippocampus include the dentate gyrus (DG) and components of cornu ammonis (CA1, CA2, CA3, and CA4 regions). The DG contains tightly arranged small granule cells, which cover the terminal part of the hippocampus near the hippocampal fissure (Mufson et al. 2015), and the CA regions contain densely packed pyramidal cells (Hyman et al. 1987). The CA4 region emerges from the DG and continues as CA3, CA2, and a narrow strip, CA1. The narrow strip of CA1 merges with the subiculum. Papez in 1937 described a circuit, which connects the cingulate gyrus to the hippocampus through the mammillary bodies and anterior thalamus. This circuit is popularly known as the Papez circuit. According to Papez, sensory inputs of emotion are transported to the hippocampus via the cingulate gyrus. The emotional expressions are organized in the hippocampus and expressed via the mammillary bodies. The hypothalamus helps in the peripheral terms of the emotional state by providing access to the autonomic outflow into the hippocampal processes. The Papez circuit is extensively involved in the mnemonic functions, spatial short-term memory, and cognitive processes (Brennan et al. 2019).

\section{Microanatomy of hippocampus}

The hippocampus is a trilaminate archicortex, which is made up of upper and lower plexiform layers, and in between these, there is a pyramidal cell layer. The CA1, CA2, CA3, and CA4 are the four fields of the hippocampus (Brennan et al. 2019). The CA3 region receives mossy fibers from the DG, and it contains about ten layers of pyramidal cells; these cells are the largest among the hippocampal pyramidal cells. The CA2 region has compactly arranged pyramidal cells, which receive significant inputs from the supra-mammillary areas of the hypothalamus. The CA1 region overlaps the subiculum, and about $10 \%$ of the neurons present in the CA1 region are interneurons. The three layers of the hippocampus are included in the six strata. These strata are named as the alveus, stratum orience, stratum pyramidalis, stratum lucidum, stratum radiatum, and stratum lacunosum-moleculare (Brennan et al. 2019). In the sub-granular layer of DG, the proliferation of neurons occurs throughout the life span. This neurogenesis is essential in the hippocampal function, like learning, long-term memory, spatial memory, and mood.

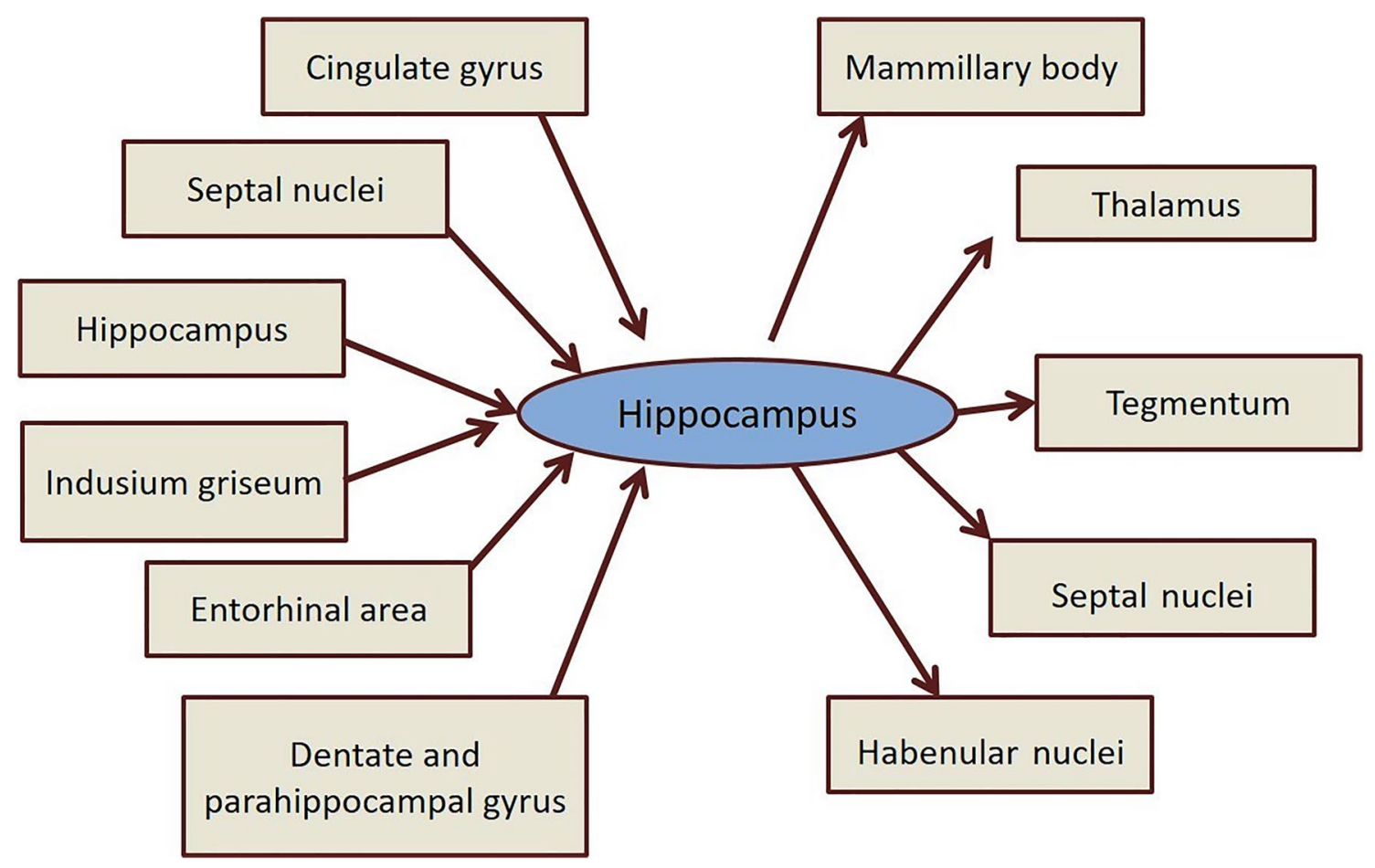

Fig. 1 Afferent and efferent connections of hippocampus 


\section{Blood supply of hippocampus}

The hippocampus is usually supplied by the branches of the posterior cerebral artery, a branch of the basilar artery, and the anterior choroidal artery, an extension of the internal carotid artery. However, the central part of the hippocampus is supplied by the posterior cerebral artery. It is also reported that the arterial supply of the hippocampus may vary in some people (Spallazzi et al. 2019). The arteries of the hippocampus are named according to their area of distribution. The anterior hippocampal artery supplies the head and uncus; the body is provided by the middle hippocampal artery, whereas the posterior hippocampal artery supplies the tail of the hippocampus. The arteries supplying the hippocampus are situated outside the ventricular cavity. On the subiculum region, which is located at the dorsal part of the para-hippocampal gyrus, the hippocampal arteries run parallel to the hippocampus and give rise to straight arteries. All these arteries enter the hippocampus at the level of DG. The anatomy of vascularisation of the hippocampus is vital to the neurosurgeons during the surgeries of this region of the brain.

\section{Connections of hippocampus (Fig. 2)}

The significant afferent connections to the hippocampus come from the entorhinal cortex via the perforant path and via the fimbria/fornix from the basal forebrain and brain stem. Supra-mammillary nucleus (SUM) and the reuniens nucleus (RE) influence the learning process and memory (Vertes 2015). The hippocampus is responsible for episodic memory. The CA2 and CA 3 regions of the hippocampus will receive input from all the sources, and

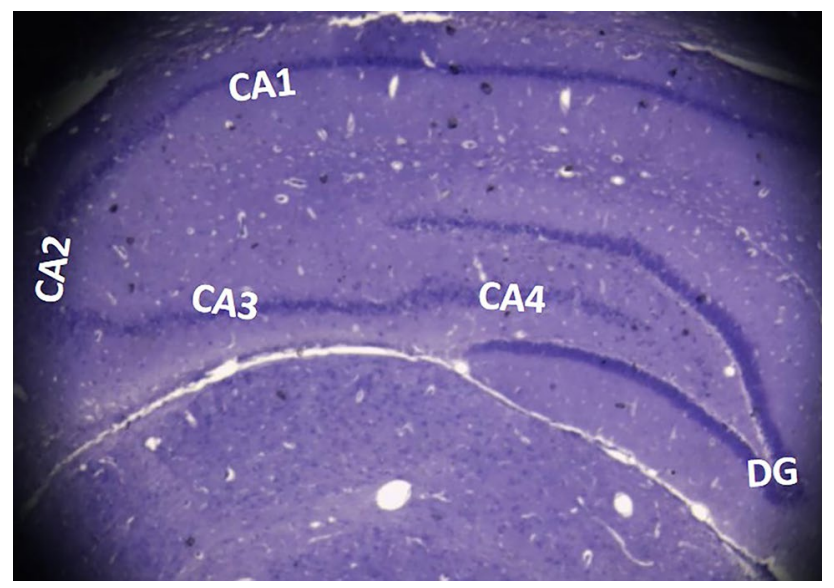

Fig. 2 Cresyl violet staining in an Albino Wistar rat model showing $(2 \mathrm{x})$ the subdivisions of hippocampus (DG-dentate gyrus; CA1cornu ammonis region 1; CA2-cornu ammonis region 2; CA3-cornu ammonis region 3; CA4-cornu ammonis region 4) this information will be segregated (Lisman et al. 2017). The association fibers from the rostrocaudal levels of the hippocampus and subcortical structures like septal nuclei and supra-mammillary regions reach the stratum radiatum and stratum orience of $\mathrm{CA} 3$ and $\mathrm{CA} 2$ regions. The projection fibers from the $\mathrm{CA} 3, \mathrm{CA} 2$, and $\mathrm{CA} 1$ areas will also reach the stratum radiatum and stratum orience. These projection fibers are called Schaffer's collaterals. The projection fibers from the entorhinal cortex travel through the stratum lacunosum-moleculare, making synapsis with the dendrites of the pyramidal cells of the hippocampus. This pathway is called the perforant pathway. It was reported that the disruption of the perforant path would lead to defects in learning and memory (Ginsberg 2010).

\section{Hippocampus and memory}

The hippocampal sub-regions aid in the process of the generation of episodic memory (Langnes et al. 2020; Collin et al. 2015). The hippocampal-dependent memory signals outline memory formation, an active and ongoing process in the brain (Voss et al. 2017). According to de Landeta et al. (2020), the retrosplenial cortex in the occipital lobe plays a role in the long-term object recognition memory, similar to the hippocampus. The CA3 region of the hippocampus produces the sharp-wave ripples (SWR), which propagate the recent memory traces into the neocortex for consolidation of the memory (Karimi Abadchi et al. 2020). Supporting de Landeta et al. (2020) opinion, Karimi Abadchi et al. (2020) also found that the maximum SWR modulation occurs in the retrosplenial cortex. The excitatory output of SWR affects a larger area of the cortex along with the subcortical nuclei. This activity occurs during the 'off-line' state of the brain (Buzsáki 2015). The hippocampus proper is responsible for episodic memory (Knierim 2015). Samuel et al. (1994) observed that the neurofibrillary tangle (NFT) accumulation in the hippocampal region is related to dementia. The NFT accumulation in the stratum lacunosum, dentate fasciculus, CA2, CA3, and CA4 areas had resulted in the synaptic loss. During the early learning stage, the neocortical prefrontal engram cells are generated by the input from the hippocampus, entorhinal cortex, and basolateral amygdala. These prefrontal engram cells, with the aid of engram cells of the hippocampus, will eventually mature. Hence, the neocortical engram cells are a critical part of remote recollection (Kitamura et al. 2017; Roy et al. 2016). The oxidative damage can reduce the cognitive function in the cortex and hippocampus (Fonzo et al. 2009). The DG is one of the brain regions which shows neurogenesis throughout the life span of a mammalian. The DG, being an information gateway, has a significant contribution to the formation of episodic 
memory of the hippocampus (Poo et al. 2016; Eriksson et al. 1998; Altman and Das 1965).

\section{Adult neurogenesis in hippocampus}

Proliferation, differentiation, and migrations are the steps involved in adult neurogenesis. The sub-granular zone of DG and the sub-ventricular zone are the two regions consisting of neural stem cells (NSCs) of the adult brain, which show neurogenesis (Abbott and Nigussie 2020). The B1 cell residues, which line the junction between the stratum and lateral ventricle, possess the astroglial property and these cell residues act as the NSCs (Horgusluoglu et al. 2017). These NSCs, responsible for adult neurogenesis, are retained in the sub-ventricular and sub-granular zone regions of the DG in the adult brain. The olfactory bulb and DG are the two regions where neurogenesis is seen throughout life (Horgusluoglu et al. 2017). In the brain, neurogenesis occurs in a niche, where the NSCs are located near the blood vessels. Therefore, signals from the existing neural cells and nearby vasculature will stimulate the NSCs for neurogenesis (Ozek et al. 2018; Shen et al. 2008). Impairment in adult neurogenesis may be a critical factor for neurodegenerative disorders like AD and Parkinson's disease. Genetic mutation, brain injury, and aging may cause depletion in the function of neural precursors (Shohayeb et al. 2018). The intrinsic factors like hormones, glia, and vascular nourishment will play a leading part in the role of NSCs by maintaining the microenvironment of the brain (Shohayeb et al. 2018; Licht and Keshet 2015).

Besides these intrinsic factors, few extrinsic factors like dietary intake and physical activity may also influence the NSCs. Hence it is understood that pro-neurogenic lifestyle could delay neurodegeneration. Neurotrophic factors (NTFs) can help the diseased neurons in AD and are offered through the viral vectors. The viral vectors can be inserted directly over that particular region, which has neuronal degeneration, and it will lead to the transduction of cells, which secrete the NTF. Besides this, stem cells may also help in neurodegenerative disorders like AD and Parkinson's disease (Shohayeb et al. 2018).

\section{Hippocampal lesions in AD}

The neuropathological abnormality in AD includes neuronal loss and gliosis at the hippocampus (Ball et al. 1985). The volumes of hippocampal layers like stratum radiatum, stratum lacunosum, stratum moleculare and subiculum's, stratum pyramidale are bilaterally lost in the patients of $\mathrm{AD}$ (Boutet et al. 2014). Though the etiology of AD is not clearly understood, the pathophysiology of $\mathrm{AD}$ demonstrates the neuro-inflammation, accumulation of $\mathrm{A} \beta$ peptides, phosphorylated tau, and oxidative stress (Reddy et al. 2017, 2012).
The entorhinal area is the first region, where the plaques and tangles are deposited in AD patients (Knierim 2015). In the early stage of $\mathrm{AD}$, tau protein gets accumulated in the entorhinal cortex and later spreads into the hippocampus (Asai et al. 2020). The anatomical and histological studies of autopsied AD brains have revealed that the neurodegeneration starts in the second layer of the entorhinal cortex and gradually extends into the hippocampus, temporal cortex, frontoparietal cortex and subcortical nuclei. In the later stages of the disease, there will be a disconnection between the DG and sub-regions of the hippocampus, leading to cognitive disorders (Reddy et al. 2018; Samuel et al. 1994; Hyman et al. 1986). Du et al. (2016) observed the accumulation of tau-1 positive foci in the polymorphic layer of the DG of rat models 7 days after the blast-induced traumatic cerebral injury. In AD, NFTs are first accumulated in the CA1 area of the hippocampus, then gradually affect the subiculum, CA2, CA3, and DG (de Flores et al. 2015; Lace et al. 2009). The tau positive neurons are associated with the $A \beta$ deposits through their axonal projections in the AD brain. It was reported that $A \beta$ deposition reduces the inputs in the hippocampus (Lace et al. 2009).

\section{Hippocampal microglia in AD}

Microglia are the resident cells of the brain, which play an essential role in regulating developmental processes like neurogenesis, axonal growth, myelination, synaptic maturation, and synaptic pruning. Microglia show significant changes during hippocampal development from the 14th postnatal day to the 28th postnatal day (Delpech et al. 2016; Parkhurst et al. 2013). The structural and functional deficiencies of genes like CX3 chemokine receptor 1 (CX3CR1), colony-stimulating factor 1 (CSF-1), methyl-CpG binding protein 2 (Mecp -2), and Homeobox B8 (Hox B8) can affect the microglia, which has an impact on the normal functioning of the central nervous system (Dantzer et al. 2008). It was reported that microglia in the hippocampal region are more immunologically active than the other regions of the brain (van Olst et al. 2020; Grabert et al. 2016). The microglial genes play an essential role in refining the neural circuits by removing the redundant synaptic connections (Rajendran and Paolicelli 2018). As innate immune effector cells, the microglia are vital in the amyloid-beta clearance (Rivera-Escalera et al. 2019). Microglial activation is a usual phenomenon during the onset of $\mathrm{AD}$ and is associated with elevated inflammatory markers in the cerebrospinal fluid (Sarlus and Heneka 2017). In the hippocampus of the AD brain, the elevation of pro-inflammatory cytokines like interleukin one $\beta$ (IL-1 $\beta$ ) will induce the microglial proliferation, which will further help remove the fibrillar $\mathrm{A} \beta$ (RiveraEscalera et al. 2019). Bachstetter et al. (2015) described that the mutations in CD33 and triggering receptors expressed 
on myeloid cell 2 (TREM2) genes could lead to AD. In the progression of $\mathrm{AD}$, atrophy of medial temporal and hippocampal regions are the structural markers in the MRI (Grabert et al. 2016). The T1- weighted scans are most commonly used, as they provide good contrast between the white and grey matter. Jacket al. (1999) observed an association between the premorbid hippocampal volume and crossing over to AD.

Microglia activation is associated with the etiopathogenesis of numerous degenerative diseases in the central nervous system (Navarro et al. 2018). It was reported that the microglial degeneration, which is observed in the DG of $\mathrm{AD}$ patients, is due to the toxic soluble phospho-tau species accumulation (Navarro et al. 2018). However, the role of microglia in AD has not been clarified (Sanchez-Mejias et al. 2016). It was described that compromised activities of the microglia and its altered response to the $\beta$-amyloid could increase the risk of AD (Hansen et al. 2018). The microglia are neuroprotective, and they act as phagocytes to engulf the $\mathrm{A} \beta$, thereby preventing $\mathrm{AD}$. The microglia are activated into disease-associated microglia (DAM) state with apolipoprotein E (apoE), which depends on the TREM2. Unfortunately, because of genetic susceptibility and aging, the function of microglia will become insufficient to prevent $\mathrm{AD}$ development. There will be an accumulation of toxic amyloid species, leading to tauopathy in the stressed and damaged neurons (Hansen et al. 2018). The microglia will be changed into an inflammatory state, leading to the engulfing of synapses and secretion of neurotoxic cytokines, eventually injuring the neurons. In the later stages of $\mathrm{AD}$, there will be synaptic loss and symptomatic decline. It was reported that microglia have dual faces, one of them is favorable, and the other is detrimental (Rao et al. 2020). This dual nature of microglial function will complicate the management protocol of $\mathrm{AD}$ since $\mathrm{AD}$ targets the microglia. The stimulation of microglia is helpful in the initial stages of $\mathrm{AD}$, which eventually becomes unfavorable during the neurodegenerative stage (Hansen et al. 2018).

\section{Growth factors and the hippocampus}

The nerve growth factor (NGF), neurotrophin 3 (NT-3), neurotrophin 4/5 (NT-4/5), and the brain-derived neurotrophic factor (BDNF) are the proteins, which specifically help the survival of neurons in AD patients (Hock et al. 2000). BDNF is one of the significant neurotrophins, which protect the neurons by promoting their survival against the various neuronal insults in different brain regions, including the hippocampus (Rai et al. 2013). The primary source for the BDNF is the neuron. Apart from the neurons, astrocytes and microglia also contain the BDNF (Lisman et al. 2017). The oxidative stress can reduce the BDNF expression, thereby leading to hippocampal atrophy. Therefore, antioxidants can reduce oxidative damage, which occurs due to the oxidative stress. It was reported that levels of ratios of NT-4/NT-3, NT-4/NT-5, and BDNF had been considerably declined at the hippocampus of AD models (Hock et al. 2000). However, the intensities of NGF/NT-3 ratio and NGF were increased at the hippocampus of $\mathrm{AD}$ animal models. Hocket al. (2000) suggested that declined intensities of the BDNF might lead to neuronal degeneration in $\mathrm{AD}$. It was reported that NGF and BDNF had protected the basal forebrain cholinergic neurons from the degeneration, which was induced by the axotomy (Knusel et al. 1992). Along with this, neurons containing 5-hydroxytryptamine are also decreased in the brain, which causes depression and behavioral changes in AD (Raskind and Peskind 1994).

\section{Growth differentiation factor (GDF) and hippocampal vasculature}

The neurogenesis occurs at the niche, where the neural stem cells (NSCs) are seen near the blood vessels. The signals from the neurons and blood vessels will influence the NSC proliferation and differentiation. Several animal experiments have shown that the systemic factors in the circulation positively influence brain neurogenesis. Ozek et al. (2018) observed that the administration of GDF 11 has improved the hippocampal vascular niche in old mice. They have also reported that systemic administration of GDF 11 has elevated the newborn neuron (Bromodeoxyuridine, $\mathrm{BrdU}^{+} /$ neuronal nuclear protein, $\mathrm{NeuN}^{+}$), neural stem cells (sexdetermining region, Sox $2^{+}$), and neural progenitor/immature neurons (doublecortin, DCX $^{+}$). Ozek et al. (2018) observed that GDF 11 had improved the vasculature of the hippocampus by increasing the blood vessels and their branches. But these improvements were honored to be only seen in the old mice brains.

It was reported that, genetic activation of activing-like kinase 5 (ALK 5) receptor for the GDF 11, has improved the neurogenesis in hippocampus by activating the downstream signalling through spinal muscular atrophy (Sma-) and mothers against decapentaplegic (Mad-)-related proteins 2/3 (SMAD 2/3). Hence, GDF11 improves hippocampal neurogenesis and vasculature (Ozek et al. 2018). The GDF11 is present in the bloodstream, with some of it crossing the blood-brain barrier (Ozek et al. 2018). It is believed to exhibit several beneficial effects on the vasculature by promoting angiogenesis, maintenance of blood-brain barrier and vascular stability (Sutherland et al. 2020). Aging will cause impaired neurogenesis due to the decreased vascular density and blood flow. The brain of elderly individuals is predisposed to many stressors, leading to irreversible brain damage. The recent trends suggest that GDF-11, which is present in young people's blood, can have neuroprotective effects (Lu et al. 2018). It was reported that the circulating 
GDF-11 in the blood decreases with the increasing age (Poggioli et al. 2016). This suggests that patients with AD may have reduced levels of GDF in their blood.

\section{Function of NSCs in hippocampus of AD patients}

NSCs have the self-renewal capacity and can differentiate into cells like neurons, oligodendrocytes, and astrocytes. The differentiated neurons help organize complex neuronal circuits, which are essential during the processing of information and transmission (Kino 2015). NSCs, after becoming the neuroglial cells like astrocytes and oligodendrocytes, will help in the proper functioning of neurons. DG of the hippocampus contains plenty of these NSCs (Androutsellis-Theotokis et al. 2008), which help in learning and memory. NSCs also increase the response to anti-depressant drugs and help in the subsequent recovery (Kino 2015). The adult NSCs in the hippocampus can grow and maintain their number throughout life (Zhang et al. 2015). NSCs are involved in consolidating, preserving, and organizing the memory, which is mediated by the hippocampus. They also assist in mood and behavioral integrity. NSCs are involved in the turnover of pyramidal cells, which is important for replacing old memory traces with new ones. NSCs are described to have their capacity in neuronal regeneration. The NSC transplantation therapy is a favourable means of managing neuronal diseases and restoration of microenvironment at the injury site (Tang et al. 2017). They secrete soluble factors, which include cytokines, growth factors, and neurotrophic factors. These factors can protect the existing neurons against the damage in situ. AD is caused by neuronal or neuroglial cell defects, resulting in memory deterioration, cognitive disorders, dementia, and body movement disorders.

It was described that hippocampal neuronal mitochondria are decreased in AD patients. The transplantation of NSCs into the transgenic AD mice model has shown a significant increase in the mitochondrial number and expression of mitochondria-related proteins. This has improved the cognitive function in a mouse model (Zhang et al. 2020). Human NSCs have been tried to treat AD in transgenic animal models (Li et al. 2016; Blurton-Jones et al. 2014). It was reported that intranasal administration of NSCs showed the ability to migrate to different regions of the central nervous system, including the hippocampus, cerebral cortex and spinal cord (Zhang et al. 2020). Though most of the parts of the brain are affected in $\mathrm{AD}$, the regions which are essential for the learning and memory like hippocampus, entorhinal cortex, and basal forebrain show marked degeneration. Decreased neurotrophin expression and its impaired neuronal transport are apparent in the neurodegenerative brain. Hence, maintaining the regular neurotrophin expression can be a treatment modality in AD management. Marsh and Blurton-Jones (2017) have demonstrated the potential benefits of NSCs in providing neurotrophic support in AD.

\section{Sirtuins and the hippocampus}

Sirtuins (SIRT), belonging to the family of histone deacetylases, are known to have a significant role in maintaining genomic stability. SIRT are classified into seven types, which are numbered from one to seven. SIRT1 is involved in neurological conditions like AD and Parkinson's disease. The pathogenic mechanism in these disorders has been linked to apoE. It is observed that the expression of apoE4 reduces the SIRT1 level. Hence, it is considered a genetic risk factor in AD (Cacabelos et al. 2019; Jęśko et al. 2017). SIRT1, a nicotinamide adenine dinucleotide + (NAD+)dependent deacetylase, acts as an intracellular regulatory protein and helps in the cell survival. SIRT1 can also preserve the mitochondrial function in the neuron and modulate the responses to DNA damage. Recent studies have reported that SIRT1 activity is increased in the rat hippocampus following the status epilepticus. Hence, activating the SIRT1 pathway may enhance the mitochondrial biogenesis and can act as an endogenous neuroprotective agent (Chuang et al. 2019).

Decreased SIRT level, particularly SIRT1, is associated with $A \beta$ deposition. Decreased levels of SIRT1 may result in the accumulation of $\mathrm{A} \beta$ peptides (Koo et al. 2017; Julien et al. 2009). Lack of SIRT1 expression in hippocampal neurons will impair cognitive function, including recent memory, spatial learning (Kumar et al. 2017). Hence, SIRT1 regulates neuronal survival, insulin sensitivity, glucose metabolism, and mitochondrial biogenesis and thus maintains neuronal homeostasis (Gomes et al. 2018; Satoh and Imai 2014; Guarente 2013). Resveratrol, an antioxidant used to manage AD, upregulates the SIRT1 and decreases the HMGB1 acetylation (Yu et al. 2019). RSV administration has decreased the levels of acetylation and expression of HMGB1 through the signaling pathway of SIRT1.

\section{Role of S100B in hippocampus}

The higher expression of S100B was observed in cases of brain injury, cerebral ischemia, and many neurological diseases, including the AD (Nishiyama et al. 2002). The S100 $\beta$ is a calcium-binding protein, expressed at a larger quantity in the brain, mainly by the astrocytes (Reeves et al. 1994). The in vitro studies have shown that S100B maintains cell structure, growth, energy metabolism, and calcium homeostasis (Zimmer et al. 1995). It has been demonstrated that, in case of brain damage, S100B is passively released in large quantities, mainly from the astrocytes. The S100B participates in amplifying the inflammatory response by further 
activating the microglia and astrocytes (Steiner et al. 2011; Donato and Heizmann 2010). It was reported that, addition of S100B dimers to primary and established cultural cells has induced extension of the neurites. This in vitro activity was also repeated in the vivo at the hippocampus of the transgenic mice model (Reeves et al. 1994). It was reported that overexpression of S100B can cause neuronal damage and mimics the signs and symptoms of $\mathrm{AD}$. The removal of S100B increases the synaptic plasticity and improves the learning and memory in the hippocampus. The long-term potentiation in the hippocampus was increased in the S100B removed mice model (Nishiyama et al. 2002).

\section{Effect of glucocorticoids and other hormones on hippocampus}

The glucocorticoid hormones secreted by the adrenal cortex because of stress can dictate cognitive function. The hippocampus is highly vulnerable to chronic exposure to endogenous glucocorticoids (Libro et al. 2017). Elevated levels of basal endogenous glucocorticoids were observed in $\mathrm{AD}$ patients. This was correlated to the dysregulation of the hypothalamic-pituitary-adrenocortical pathway and the degeneration of the hippocampus and decreased cognitive and memory function. The pre-clinical studies have demonstrated that higher endogenous glucocorticoids can lead to amyloid-beta $(\mathrm{A} \beta)$ in the $\mathrm{AD}$ rat models by facilitating the amyloidogenic pathway. The clearance of $A \beta$ through transcriptional mechanisms of glucocorticoid receptors is also decreased (Libro et al. 2017). It has been demonstrated that dexamethasone decreases the dendritic spine density and induces the proliferation and activation of microglia in the CA1 region in the triple-transgenic mouse model $(3 \times \mathrm{Tg}-$ $\mathrm{AD})$ mice. Exposure to chronic stress and subsequent oversecretion of glucocorticoids severely impacts the synaptic structure, function, and plasticity in the hippocampus (Canet et al. 2018).

Hormones act as signalling factors for the neuroendocrine system, which modulate adult neurogenesis. There is a close relationship between the sex hormones and hippocampal neuronal proliferation in the hippocampus. It was reported that; increased level of ovarian hormones had increased the cell proliferation in the sub-granular region. Decreased levels of testosterone had reduced the capacity of new neuron production (Shohayeb et al. 2018). It is also demonstrated that mifepristone strongly enhances the dendritic spine density and improves the behavioral performance of $3 \times \mathrm{Tg}-\mathrm{AD}$ mice (Pedrazzoli et al. 2019). In the oligomeric amyloid- $\beta$ peptide (oA $\beta 25-35)$ rat model, mifepristone restored the basal levels of circulating corticosterone levels and repaired the apoptosis and synaptic deficits in the hippocampus (Canet et al. 2018).

\section{Proneurogenic lifestyle and neuronal degeneration}

The lifestyle controls the human brain's function. Physical activity, food habits, and exposure to stress can impact the cognitive reserve of the brain. The animal model research has shown that running exercise can increase the hippocampal neurogenesis. The pro-neurogenic lifestyle will control the capability of the brain to prevent the neuronal degeneration due to the trauma, aging, and diseases (Valero et al. 2016). It was reported that, the low calorie diet and physical exercise can promote the adult neurogenesis. The omega-3 polyunsaturated fatty acids are required for the proper neuronal function as they exert an anti-inflammatory effect (Valero et al. 2016). It was reported that physical activity has prevented the decline of neurogenesis and boosted the memory in aged rodents and mouse AD models (van Praag 2008). Stress and severe exercise can elevate the glucocorticoids and affect the microglia (Gleeson et al. 2011). Both acute and chronic stresses decrease the adult neurogenesis due to the reduction in proliferation of neuroprogenitor cells and survival of newborn cells (Schoenfeld and Gould 2012). Animal research has shown that the high fatty diet has decreased the cell proliferation, cell survival and increased apoptosis in the DG (Park et al. 2011). It was observed that the high-fat diet decreased the BDNF and omega-3 polyunsaturated fatty acids increased it. This suggests that diet has a role in the maintenance of BDNF levels. Obesity and high-fat diet are associated with the state of chronic systemic inflammation, which increases the levels of proinflammatory cytokines like IL1- $\beta$ and tumor necrosis factor $\alpha(\mathrm{TNF} \alpha)$ by the adipose tissue (Gregor and Hotamisligil 2011).

\section{Conclusion}

The devastating neuronal loss and gliosis in the hippocampus are the hallmark of AD. The advanced shrinkage of the hippocampus is accountable for the short-term memory loss. The microglia in the brain phagocytose the $\mathrm{A} \beta$ aggregates and clears them from the neurons. But the microglia have dual nature as they help initially by phagocytosing the cellular debris in the brain and become harmful in the later stages of this degenerative disorder. Future studies, which throw insight into the microglial functions, will help understand AD's management. The local and extrinsic environmental factors highly regulate hippocampal neurogenesis. Physical exercise, growth factors, and even hormones can influence neuronal production and survival in the DG, which controls the hippocampal-dependent cognitive and emotional functions. 
Funding Open access funding provided by Manipal Academy of Higher Education, Manipal.

\section{Declarations}

Conflict of interest The authors of this manuscript declare that there are no conflicts of interest associated with this manuscript.

Open Access This article is licensed under a Creative Commons Attribution 4.0 International License, which permits use, sharing, adaptation, distribution and reproduction in any medium or format, as long as you give appropriate credit to the original author(s) and the source, provide a link to the Creative Commons licence, and indicate if changes were made. The images or other third party material in this article are included in the article's Creative Commons licence, unless indicated otherwise in a credit line to the material. If material is not included in the article's Creative Commons licence and your intended use is not permitted by statutory regulation or exceeds the permitted use, you will need to obtain permission directly from the copyright holder. To view a copy of this licence, visit http://creativecommons.org/licenses/by/4.0/.

\section{References}

Abbott LC, Nigussie F (2020) Adult neurogenesis in the mammalian dentate gyrus. Anat Histol Embryol 49(1):3-16

Altman J, Das GD (1965) Autoradiographic and histological evidence of postnatal hippocampal neurogenesis in rats. J Comp Neurol 124(3):319-335

Androutsellis-Theotokis A, Murase S, Boyd JD, Park DM, Hoeppner DJ, Ravin R, McKay RD (2008) Generating neurons from stem cells. Methods Mol Biol 438:31-38

Asai H, Ohkawa N, Saitoh Y, Ghandour K, Murayama E, Nishizono H, Matsuo M, Hirayama T, Kaneko R, Muramatsu SI, Yagi T, Inokuchi K (2020) Pcdh $\beta$ deficiency affects hippocampal CA1 ensemble activity and contextual fear discrimination. Mol Brain 13(1):7

Bachstetter AD, Van Eldik LJ, Schmitt FA, Neltner JH, Ighodaro ET, Webster SJ, Patel E, Abner EL, Kryscio RJ, Nelson PT (2015) Disease-related microglia heterogeneity in the hippocampus of Alzheimer's disease, dementia with Lewy bodies, and hippocampal sclerosis of aging. Acta Neuropathol Commun 3:32

Ball MJ, Fisman M, Hachinski V, Blume W, Fox A, Kral VA, Kirshen AJ, Fox H, Merskey H (1985) A new definition of Alzheimer's disease: a hippocampal dementia. Lancet 1(8419):14-16

Blurton-Jones M, Spencer B, Michael S, Castello NA, Agazaryan AA, Davis JL, Müller FJ, Loring JF, Masliah E, LaFerla FM (2014) Neural stem cells genetically-modified to express neprilysin reduce pathology in Alzheimer transgenic models. Stem Cell Res Ther 5(2):46

Boutet C, Chupin M, Lehéricy S, Marrakchi-Kacem L, Epelbaum S, Poupon C, Wiggins C, Vignaud A, Hasboun D, Defontaines B, Hanon O, Dubois B, Sarazin M, Hertz-Pannier L, Colliot O (2014) Detection of volume loss in hippocampal layers in Alzheimer's disease using 7 T MRI: a feasibility study. Neuroimage Clin 5:341-348

Brennan P, Standring S, Wiseman S (2019) Gray's surgical anatomy e-book. Elsevier Health Sciences

Buzsáki G (2015) Hippocampal sharp wave-ripple: a cognitive biomarker for episodic memory and planning. Hippocampus 25(10): 1073-1188

Cacabelos R, Carril JC, Cacabelos N, Kazantsev AG, Vostrov AV, Corzo L, Cacabelos P, Goldgaber D (2019) Sirtuins in Alzheimer's disease: SIRT2-related genophenotypes and implications for pharmacoepigenetics. Int J Mol Sci 20(5):1249

Canet G, Chevallier N, Zussy C, Desrumaux C, Givalois L (2018) Central role of glucocorticoid receptors in Alzheimer's disease and depression. Front Neurosci 12:739

Chu LW (2012) Alzheimer's disease: early diagnosis and treatment. Hong Kong Med J 18(3):228-237

Chuang YC, Chen SD, Jou SB, Lin TK, Chen SF, Chen NC, Hsu CY (2019) Sirtuin 1 regulates mitochondrial biogenesis and provides an endogenous neuroprotective mechanism against seizureinduced neuronal cell death in the hippocampus following status epilepticus. Int J Mol Sci 20(14):3588

Collin SH, Milivojevic B, Doeller CF (2015) Memory hierarchies map onto the hippocampal long axis in humans. Nat Neurosci 18(11):1562-1564

Dantzer R, O’Connor JC, Freund GG, Johnson RW, Kelley KW (2008) From inflammation to sickness and depression: when the immune system subjugates the brain. Nat Rev Neurosci 9(1):46-56

de Flores R, La Joie R, Chételat G (2015) Structural imaging of hippocampal subfields in healthy aging and Alzheimer's disease. Neuroscience 309:29-50

de Landeta AB, Pereyra M, Medina JH, Katche C (2020) Anterior retrosplenial cortex is required for long-term object recognition memory. Sci Rep 10(1):4002

Delpech JC, Wei L, Hao J, Yu X, Madore C, Butovsky O, Kaffman A (2016) Early life stress perturbs the maturation of microglia in the developing hippocampus. Brain Behav Immun 57:79-93

Donato R, Heizmann CW (2010) S100B protein in the nervous system and cardiovascular apparatus in normal and pathological conditions. Cardiovasc Psychiatry Neurol 2010:929712

Du X, West MB, Cheng W, Ewert DL, Li W, Saunders D, Towner RA, Floyd RA, Kopke RD (2016) Ameliorative effects of antioxidants on the hippocampal accumulation of pathologic tau in a rat model of blast-induced traumatic brain injury. Oxid Med Cell Longev 2016:4159357

Elder GJ, Mactier K, Colloby SJ, Watson R, Blamire AM, O’Brien JT, Taylor JP (2017) The influence of hippocampal atrophy on the cognitive phenotype of dementia with Lewy bodies. Int J Geriatr Psychiatry 32(11):1182-1189

Eriksson PS, Perfilieva E, Björk-Eriksson T, Alborn A, Nordborg C, Peterson DA, Gage FH (1998) Neurogenesis in the adult human hippocampus. Nat Med 4(11):1313-1317

Fonzo LS, Golini RS, Delgado SM, Ponce IT, Bonomi MR, Rezza IG, Gimenez MS, Anzulovich AC (2009) Temporal patterns of lipoperoxidation and antioxidant enzymes are modified in the hippocampus of vitamin A-deficient rats. Hippocampus 19(9):869-880

Ginsberg SD (2010) Alterations in discrete glutamate receptor subunits in adult mouse dentate gyrus granule cells following perforant path transection. Anal Bioanal Chem 397(8):3349-3358

Gleeson M, Bishop NC, Stensel DJ, Lindley MR, Mastana SS, Nimmo MA (2011) The anti-inflammatory effects of exercise: mechanisms and implications for the prevention and treatment of disease. Nat Rev Immunol 11:607-615

Gomes BAQ, Silva JPB, Romeiro CFR, Dos Santos SM, Rodrigues CA, Gonçalves PR, Sakai JT, Mendes PFS, Varela ELP, Monteiro MC (2018) Neuroprotective mechanisms of resveratrol in Alzheimer's disease: role of SIRT1. Oxid Med Cell Longev 2018:8152373

Grabert K, Michoel T, Karavolos MH, Clohisey S, Baillie JK, Stevens MP, Freeman TC, Summers KM, McColl BW (2016) Microglial brain region-dependent diversity and selective regional sensitivities to aging. Nat Neurosci 19(3):504-516

Gregor MF, Hotamisligil GS (2011) Inflammatory mechanisms in obesity. Annu Rev Immunol 29:415-445 
Guarente L (2013) Calorie restriction and sirtuins revisited. Genes Dev 27(19):2072-2085

Hansen DV, Hanson JE, Sheng M (2018) Microglia in Alzheimer's disease. J Cell Biol 217(2):459-472

Hock C, Heese K, Hulette C, Rosenberg C, Otten U (2000) Regionspecific neurotrophin imbalances in Alzheimer disease: decreased levels of brain-derived neurotrophic factor and increased levels of nerve growth factor in hippocampus and cortical areas. Arch Neurol 57(6):846-851

Horgusluoglu E, Nudelman K, Nho K, Saykin AJ (2017) Adult neurogenesis and neurodegenerative diseases: a systems biology perspective. Am J Med Genet B Neuropsychiatr Genet 174(1):93-112

Hu K, Li Y, Yu H, Hu Y (2019) CTBP1 confers protection for hippocampal and cortical neurons in rat models of Alzheimer's disease. NeuroImmunoModulation 26(3):139-152

Hyman BT, Van Hoesen GW, Kromer LJ, Damasio AR (1986) Perforant pathway changes and the memory impairment of Alzheimer's disease. Ann Neurol 20(4):472-481

Hyman BT, Van Hoesen GW, Damasio AR (1987) Alzheimer's disease: glutamate depletion in the hippocampal perforant pathway zone. Ann Neurol 22(1):37-40

Jack CR Jr, Petersen RC, Xu YC, O'Brien PC, Smith GE, Ivnik RJ, Boeve BF, Waring SC, Tangalos EG, Kokmen E (1999) Prediction of AD with MRI-based hippocampal volume in mild cognitive impairment. Neurology 52(7):1397-1403

Jaroudi W, Garami J, Garrido S, Hornberger M, Keri S, Moustafa AA (2017) Factors underlying cognitive decline in old age and Alzheimer's disease: the role of the hippocampus. Rev Neurosci 28(7):705-714

Jęśko H, Wencel P, Strosznajder RP, Strosznajder JB (2017) Sirtuins and their roles in brain aging and neurodegenerative disorders. Neurochem Res 42(3):876-890

Josephs KA, Dickson DW, Tosakulwong N, Weigand SD, Murray ME, Petrucelli L, Liesinger AM, Senjem ML, Spychalla AJ, Knopman DS, Parisi JE, Petersen RC, Jack CR Jr, Whitwell JL (2017) Rates of hippocampal atrophy and presence of post-mortem TDP-43 in patients with Alzheimer's disease: a longitudinal retrospective study. Lancet Neurol 16(11):917-924

Julien C, Tremblay C, Emond V, Lebbadi M, Salem N Jr, Bennett DA, Calon F (2009) Sirtuin 1 reduction parallels the accumulation of tau in Alzheimer disease. J Neuropathol Exp Neurol 68(1):48-58

Karimi Abadchi J, Nazari-Ahangarkolaee M, Gattas S, BermudezContreras E, Luczak A, McNaughton BL, Mohajerani MH (2020) Spatiotemporal patterns of neocortical activity around hippocampal sharp-wave ripples. Elife 9:e51972

Kino T (2015) Stress, glucocorticoid hormones, and hippocampal neural progenitor cells: implications to mood disorders. Front Physiol 6:230

Kitamura T, Ogawa SK, Roy DS, Okuyama T, Morrissey MD, Smith LM, Redondo RL, Tonegawa S (2017) Engrams and circuits crucial for systems consolidation of a memory. Science 356(6333):73-78

Knierim JJ (2015) The hippocampus. Curr Biol CB 25(23):R1116-1121

Knüsel B, Beck KD, Winslow JW, Rosenthal A, Burton LE, Widmer HR, Nikolics K, Hefti F (1992) Brain-derived neurotrophic factor administration protects basal forebrain cholinergic but not nigral dopaminergic neurons from degenerative changes after axotomy in the adult rat brain. J Neurosci 12(11):4391-4402

Koo JH, Kang EB, Oh YS, Yang DS, Cho JY (2017) Treadmill exercise decreases amyloid- $\beta$ burden possibly via activation of SIRT-1 signaling in a mouse model of Alzheimer's disease. Exp Neurol 288:142-152

Kumar R, Nigam L, Singh AP, Singh K, Subbarao N, Dey S (2017) Design, synthesis of allosteric peptide activator for human SIRT1 and its biological evaluation in cellular model of Alzheimer's disease. Eur J Med Chem 127:909-916
Lace G, Savva GM, Forster G, de Silva R, Brayne C, Matthews FE, Barclay JJ, Dakin L, Ince PG, Wharton SB, MRC-CFAS (2009) Hippocampal tau pathology is related to neuroanatomical connections: an ageing population-based study. Brain $132(\mathrm{Pt}$ 5):1324-1334

Lancaster TM, Hill MJ, Sims R, Williams J (2019) Microglia-mediated immunity partly contributes to the genetic association between Alzheimer's disease and hippocampal volume. Brain Behav Immunity 79:267-273

Langnes E, Sneve MH, Sederevicius D, Amlien IK, Walhovd KB, Fjell AM (2020) Anterior and posterior hippocampus macro-and microstructure across the lifespan in relation to memory-A longitudinal study. Hippocampus 30(7):678-692

Li X, Zhu H, Sun X, Zuo F, Lei J, Wang Z, Bao X, Wang R (2016) Human neural stem cell transplantation rescues cognitive defects in APP/PS1 model of Alzheimer's disease by enhancing neuronal connectivity and metabolic activity. Front Aging Neurosci 8:282

Libro R, Bramanti P, Mazzon E (2017) Endogenous glucocorticoids: role in the etiopathogenesis of Alzheimer's disease. Neuro Endocrinol Lett 38(1):1-12

Licht T, Keshet E (2015) The vascular niche in adult neurogenesis. Mech Dev 138:56-62

Lisman J, Buzsáki G, Eichenbaum H, Nadel L, Ranganath C, Redish AD (2017) Viewpoints: how the hippocampus contributes to memory, navigation, and cognition. Nat Neurosci 20(11):1434-1447

Lu L, Bai X, Cao Y, Luo H, Yang X, Kang L, Shi MJ, Fan W, Zhao BQ (2018) Growth differentiation factor 11 promotes neurovascular recovery after stroke in mice. Front Cell Neurosci 12:205

Marsh SE, Blurton-Jones M (2017) Neural stem cell therapy for neurodegenerative disorders: the role of neurotrophic support. Neurochem Int 106:94-100

Mufson EJ, Mahady L, Waters D, Counts SE, Perez SE, DeKosky ST, Ginsberg SD, Ikonomovic MD, Scheff SW, Binder LI (2015) Hippocampal plasticity during the progression of Alzheimer's disease. Neuroscience 309:51-67

Navarro V, Sanchez-Mejias E, Jimenez S, Muñoz-Castro C, SanchezVaro R, Davila JC, Vizuete M, Gutierrez A, Vitorica J (2018) Microglia in Alzheimer's disease: activated dysfunctional or degenerative. Front Aging Neurosci 10:140

Nishiyama H, Knopfel T, Endo S, Itohara S (2002) Glial protein S100B modulates long-term neuronal synaptic plasticity. Proc Natl Acad Sci USA 99(6):4037-4042

Ozek C, Krolewski RC, Buchanan SM, Rubin LL (2018) Growth differentiation factor 11 treatment leads to neuronal and vascular improvements in the hippocampus of aged mice. Sci Rep 8(1):17293

Park HR, Kim JY, Park KY, Lee J (2011) Lipotoxicity of palmitic acid on neural progenitor cells and hippocampal neurogenesis. Toxicol Res 27:103-110

Parkhurst CN, Yang G, Ninan I, Savas JN, Yates JR 3rd, Lafaille JJ, Hempstead BL, Littman DR, Gan WB (2013) Microglia promote learning-dependent synapse formation through brain-derived neurotrophic factor. Cell 155(7):1596-1609

Pedrazzoli M, Losurdo M, Paolone G, Medelin M, Jaupaj L, Cisterna B, Slanzi A, Malatesta M, Coco S, Buffelli M (2019) Glucocorticoid receptors modulate dendritic spine plasticity and microglia activity in an animal model of Alzheimer's disease. Neurobiol Dis 132:104568

Poggioli T, Vujic A, Yang P, Macias-Trevino C, Uygur A, Loffredo FS, Pancoast JR, Cho M, Goldstein J, Tandias RM, Gonzalez E, Walker RG, Thompson TB, Wagers AJ, Fong YW, Lee RT (2016) Circulating growth differentiation factor 11/8 levels decline with age. Circ Res 118(1):29-37

Poo MM, Pignatelli M, Ryan TJ, Tonegawa S, Bonhoeffer T, Martin KC, Rudenko A, Tsai LH, Tsien RW, Fishell G, Mullins C, Gonçalves JT, Shtrahman M, Johnston ST, Gage FH, Dan Y, Long J,

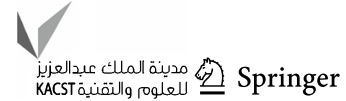


Buzsáki G, Stevens C (2016) What is memory? The present state of the engram. BMC Biol 14:40

Rai AR, Madhyastha S, Rao GM, Rai R, Sahu SS (2013) A comparison of resveratrol and vitamin $\mathrm{C}$ therapy on expression of BDNF in stressed rat brain homogenate. IOSR J Pharm 10:22-27

Rajendran L, Paolicelli RC (2018) Microglia-mediated synapse loss in Alzheimer's disease. J Neurosc 38(12):2911-2919

Rao YL, Ganaraja B, Joy T, Pai MM, Ullal SD, Murlimanju BV (2020) Neuroprotective effects of resveratrol in Alzheimer's disease. Front Biosci (elite Ed) 12:139-149

Raskind MA, Peskind ER (1994) Neurobiology bases of noncognitive behavioral problems in Alzheimer disease. Alzheimer Dis Assoc Disord 8(Suppl 3):54-60

Reddy PH, Tripathi R, Troung Q, Tirumala K, Reddy TP, Anekonda V, Shirendeb UP, Calkins MJ, Reddy AP, Mao P, Manczak M (2012) Abnormal mitochondrial dynamics and synaptic degeneration as early events in Alzheimer's disease: implications to mitochondria-targeted antioxidant therapeutics. Biochim Biophys Acta 5:639-649

Reddy PH, Tonk S, Kumar S, Vijayan M, Kandimalla R, Kuruva CS, Reddy AP (2017) A critical evaluation of neuroprotective and neurodegenerative MicroRNAs in Alzheimer's disease. Biochem Biophys Res Commun 483(4):1156-1165

Reddy PH, Yin X, Manczak M, Kumar S, Pradeepkiran JA, Vijayan M, Reddy AP (2018) Mutant APP and amyloid beta-induced defective autophagy, mitophagy, mitochondrial structural and functional changes and synaptic damage in hippocampal neurons from Alzheimer's disease. Hum Mol Genet 27(14):2502-2516

Reeves RH, Yao J, Crowley MR, Buck S, Zhang X, Yarowsky P, Gearhart JD, Hilt DC (1994) Astrocytosis and axonal proliferation in the hippocampus of S100b transgenic mice. Proc Natl Acad Sci USA 91(12):5359-5363

Rivera-Escalera F, Pinney JJ, Owlett L, Ahmed H, Thakar J, Olschowka JA, Elliott MR, O’Banion MK (2019) IL-1 $\beta$-driven amyloid plaque clearance is associated with an expansion of transcriptionally reprogrammed microglia. J Neuroinflammation 16(1):261

Roy DS, Arons A, Mitchell TI, Pignatelli M, Ryan TJ, Tonegawa S (2016) Memory retrieval by activating engram cells in mouse models of early Alzheimer's disease. Nature 531(7595):508-512

Ruan Q, D'Onofrio G, Sancarlo D, Bao Z, Greco A, Yu Z (2016) Potential neuroimaging biomarkers of pathologic brain changes in Mild Cognitive Impairment and Alzheimer's disease: a systematic review. BMC Geriatr 16:104

Samuel W, Masliah E, Hill LR, Butters N, Terry R (1994) Hippocampal connectivity and Alzheimer's dementia: effects of synapse loss and tangle frequency in a two-component model. Neurology 44(11):2081-2088

Sanchez-Mejias E, Navarro V, Jimenez S, Sanchez-Mico M, SanchezVaro R, Nuñez-Diaz C, Trujillo-Estrada L, Davila JC, Vizuete M, Gutierrez A, Vitorica J (2016) Soluble phospho-tau from Alzheimer's disease hippocampus drives microglial degeneration. Acta Neuropathol 132(6):897-916

Sarlus H, Heneka MT (2017) Microglia in Alzheimer's disease. J Clin Investig 127(9):3240-3249
Satoh A, Imai S (2014) Hypothalamic Sirt1 in aging. Aging 6(1):1-2 Schoenfeld T, Gould E (2012) Stress, stress hormones, and adult neurogenesis. Exp Neurol 233:12-21

Shen Q, Wang Y, Kokovay E, Lin G, Chuang SM, Goderie SK, Roysam B, Temple S (2008) Adult SVZ stem cells lie in a vascular niche: a quantitative analysis of niche cell-cell interactions. Cell Stem Cell 3(3):289-300

Shohayeb B, Diab M, Ahmed M, Ng DCH (2018) Factors that influence adult neurogenesis as potential therapy. Transl Neurodegener 7:4

Spallazzi M, Dobisch L, Becke A, Berron D, Stucht D, Oeltze-Jafra S, Caffarra P, Speck O, Düzel E (2019) Hippocampal vascularization patterns: a high-resolution 7 Tesla time-of-flight magnetic resonance angiography study. NeuroImage Clin 21:101609

Steiner J, Bogerts B, Schroeter ML, Bernstein HG (2011) S100B protein in neurodegenerative disorders. Clin Chem Lab Med 49(3):409-424

Sutherland BA, Hadley G, Alexopoulou Z, Lodge TA, Neuhaus AA, Couch Y, Kalajian N, Morten KJ, Buchan AM (2020) Growth differentiation factor-11 causes neurotoxicity during ischemia in vitro. Front Neurol 11:1023

Tang Y, Yu P, Cheng L (2017) Current progress in the derivation and therapeutic application of neural stem cells. Cell Death Dis 8:e3108

Valero J, Paris I, Sierra A (2016) Lifestyle shapes the dialogue between environment, microglia, and adult neurogenesis. ACS Chem Neurosci 7(4):442-453

van Praag H (2008) Neurogenesis and exercise: past and future directions. Neurol Med 10:128-140

van Olst L, Verhaege D, Franssen M, Kamermans A, Roucourt B, Carmans S, Ytebrouck E, van der Pol SMA, Wever D, Popovic M, Vandenbroucke RE, Sobrino T, Schouten M, de Vries HE (2020) Microglial activation arises after aggregation of phosphorylatedtau in a neuron-specific P301S tauopathy mouse model. Neurobiol Aging 89:89-98

Vertes RP (2015) Major diencephalic inputs to the hippocampus: supramammillary nucleus and nucleus reuniens. Circuitry and function. Prog Brain Res 219:121-144

Voss JL, Bridge DJ, Cohen NJ, Walker JA (2017) A closer look at the hippocampus and memory. Trends Cogn Sci 21(8):577-588

Yu S, Zhou X, Xiang H, Wang S, Cui Z, Zhou J (2019) Resveratrol reduced liver damage after liver resection in a rat model by upregulating SIRTUIN 1 (SIRT1) and inhibiting the acetylation of high mobility group box 1 (HMGB1). Med Sci Monit 25:3212-3220

Zhang W, Gu GJ, Shen X, Zhang Q, Wang GM, Wang PJ (2015) Neural stem cell transplantation enhances mitochondrial biogenesis in a transgenic mouse model of Alzheimer's disease-like pathology. Neurobiol Aging 36:1282-1292

Zhang Y, Zhao Y, Song X, Luo H, Sun J, Han C, Gu X, Li J, Cai G, Zhu Y, Liu Z, Wei L, Wei ZZ (2020) Modulation of stem cells as therapeutics for severe mental disorders and cognitive impairments. Front Psychiatry 11:80

Zimmer DB, Cornwall EH, Landar A, Song W (1995) The S100 protein family: history, function, and expression. Brain Res Bull $37: 417-429$ 